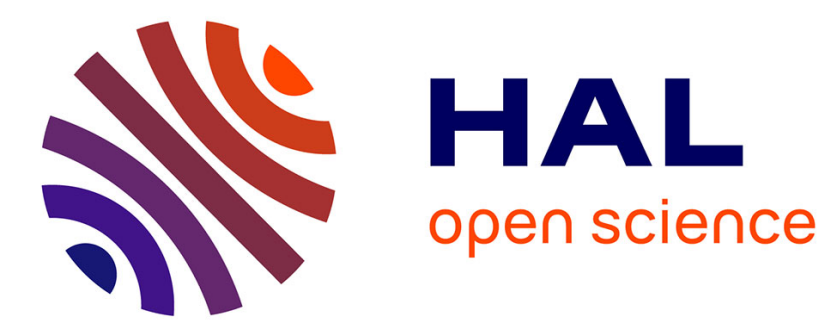

\title{
Wood decay at sea
}

François Charles, Jennifer Coston-Guarini, Jean-Marc Guarini, Sandrine

Fanfard

\section{To cite this version:}

François Charles, Jennifer Coston-Guarini, Jean-Marc Guarini, Sandrine Fanfard. Wood decay at sea. Journal of Sea Research (JSR), 2016, 114, pp.22-25. 10.1016/j.seares.2016.05.002 . hal-01321467

\section{HAL Id: hal-01321467 https://hal.sorbonne-universite.fr/hal-01321467}

Submitted on 25 May 2016

HAL is a multi-disciplinary open access archive for the deposit and dissemination of scientific research documents, whether they are published or not. The documents may come from teaching and research institutions in France or abroad, or from public or private research centers.
L'archive ouverte pluridisciplinaire HAL, est destinée au dépôt et à la diffusion de documents scientifiques de niveau recherche, publiés ou non, émanant des établissements d'enseignement et de recherche français ou étrangers, des laboratoires publics ou privés. 
Title:

Wood decay at sea

Author names and affiliations:

François Charles $^{\mathrm{a}, \mathrm{b},{ }^{*}}$, Jennifer Coston-Guarini ${ }^{\mathrm{c}, \mathrm{d}}$, Jean-Marc Guarini ${ }^{\mathrm{a}, \mathrm{b}}$, Sandrine Fanfard ${ }^{\mathrm{a}, \mathrm{b}}$.

a. CNRS, UMR8222, Laboratoire d'Ecogéochimie des Environnements Benthiques, F-66650,

Banyuls/mer, France

b. Sorbonne Universités, UPMC Univ Paris 06, UMR 8222, LECOB, Observatoire océanologique, F66650, Banyuls/mer, France

c. UMR 6539, LEMAR, Université de Bretagne Occidentale, Institut Universitaire Européen de la Mer, Technopole Brest-Iroise, rue Dumont d’Urville, 29280 Plouzané, France

d. The Entangled Bank Laboratory, EBLab, F-66650 Banyuls/Mer, France

* corresponding author

charles@obs-banyuls.fr

jennifer.coston@univ-brest.fr

guarini.jm.upmc@gmail.com

sandrine.fanfard@icloud.com 


\section{Abstract:}

The oceans and seas receive coarse woody debris since the Devonian, but the kinetics of wood degradation remains one of many unanswered questions about the fate of driftwood in the marine environment. A simple gravimetric experiment was carried out at a monitoring station located at the exit of a steep, forested Mediterranean watershed in the Eastern Pyrenees. The objective was to describe and quantify, with standardized logs (in shape, structure and constitution), natural degradation of wood in the sea. Results show that the mass decrease of wood logs over time can be described by a sigmoidal curve. The primary process of wood decay observed at the monitoring station was due to the arrival and installation of woodboring species that consumed more than half of the total wood mass in six months. Surprisingly, in a region where there is little remaining wood marine infrastructure, "shipworms", i.e. xylophagous bivalves, are responsible for an important part of this wood decay. This suggests that these communities are maintained probably by a frequent supply of a large quantity of riparian wood entering the marine environment adjacent to the watershed. By exploring this direct link between terrestrial and marine ecosystems, our long term objective is to determine how these supplies of terrestrial organic carbon can sustain woodbased marine communities as it is observed in the Mediterranean Sea.

Key-words: Coarse woody debris, Decay dynamics, Shipworm, Mediterranean Sea 


\section{Introduction}

Wood found in the marine environment was either carried by river discharge from forested watersheds, directly produced in mangroves, accidentally spilled during shipping, or used in infrastructure (e.g., boats, piers, wharfs). Adrift or submerged, coarse wood debris (CWD) increase the structural complexity of habitats, serving many ecological functions. CWD are known to host a broad spectrum of marine life and contribute to the dispersion of sessile or non-swimming species (Thiel and Haye, 2006). They constitute a source of energy and nutrients for marine ecosystems (Bienhold et al., 2013) and provide a nucleation point for mineral deposition in near-anaerobic conditions (Charles et al., 2014; Fors et al., 2014). However, few studies have considered the transfer and fate of CWD at sea (Dickinson and Pugh, 1974; Thiel et al., 2011; West et al., 2011). This lack of information partly arises from the difficulty to quantify inputs because CWD fluxes vary widely in space and time for both ecological and socio-economic reasons. And technical challenges, such as the long experiments required for the measurement of wood structural complexity and subsequent decomposition (Björdal and Nilsson, 2008) may have impeded measurements and observations too. Hence, there is no study that specifically deals with dynamics of wood decay at sea. Most studies state that degradation of wood in marine environments is fast, but only some provide indirect estimations of the actual rate of decay (Bienhold et al., 2013; Amon et al., 2015). To our knowledge, no study has dealt with the dynamics of wood decay under marine conditions, as was done for terrestrial and aquatic habitats (Harmon et al., 1986; Spänhoff and Meyer, 2004; Freschet et al., 2012).

CWD decay in marine environments is a complex process (Fojutowski et al., 2014) which depends not only on environmental factors such as oxygen concentration, water temperature and salinity, but also on the properties of individual wood pieces (Björdal and 
Nilsson, 2008). As a consequence, no single, unified function to describe wood decay at sea can be formulated, and curves fitted to observations cannot be transposed to other cases since they do not account for the full complexity and diversity of all wood decay processes (Webster and Benfield, 1986; Freschet et al., 2012). Invertebrates, for instance, can be essential for the degradation activity of wood by decomposers (Bienhold et al., 2013). Marine environments support several wood borers which appear very effective in the disintegration of wood pieces (Björdal and Nilsson, 2008; Nishimoto et al., 2015), but once again, there is no general study on how fast wood breaks down under the activity of these organisms.

The aim of our study was to describe and quantify decay rates of wood at sea. By implementing a simple gravimetric experiment at the exit of a steep, forested Mediterranean watershed, we have monitored the decay of standardized pieces of pine sapwood, Pinus sylvestris, for thirteen months. The objective was to build a consistent quantitative description of loss of CWD mass over time linked with the colonization of marine wood-borers.

2. Material and methods

Wood mass loss study

The experiment took place from April 18, 2014 to May 25, 2015 at the mouth of a small torrential Mediterranean river called "La Massane", which drains a forested watershed in the foothills of the French eastern Pyrenees, in the south of the Gulf of Lions. Sapwood of Pinus sylvestris was chosen for this experiment. This softwood species is widespread in Europe and most commonly used for general construction. Under a Mediterranean climate, it occurs in the mountains where weather conditions are cooler and soils are moister than in the plain (Sabaté et al., 2002).

Twenty blocks were manufactured in dimensions of: 150(L) x 34(T) x 34(R) mm (Llength, T-tangential, R-radial) from untreated planed cleats (2400 x 34 x $34 \mathrm{~mm})$. The 
volumetric mass density of the wood was $552 \mathrm{~kg} \mathrm{~m}^{-3}$ and the average number of annual growth rings on a cross section was 4 per $\mathrm{cm}$. Each wood piece was drilled once perpendicular to the longest dimension (diameter: $7 \mathrm{~mm}$ ) to attach a rope. The blocks were then oven dried $50{ }^{\circ} \mathrm{C}+/-5{ }^{\circ} \mathrm{C}$ for five days and individually weighed.

The dried, weighed wooden blocks were then arranged by sets of five along four rope lines for installation at the field site $\left(42^{\circ} 32^{\prime} 34.80 \mathrm{~N}, 3^{\circ} 3^{\prime} 8.38 \mathrm{E}\right)$. In order to determine mass loss of an individual wood block, each line was labelled (1 to 4$)$ and the position of the wood blocks (1 to 5) along each line was recorded. Lines were weighted at one end and attached at the other end to a floating pontoon in such a way that the wood lines remained entirely submerged between one meter and one meter and a half below the water surface.

The lines were then randomly sampled after 97, 146, 208 and 402 days. Temperature and salinity were measured at $0.6 \mathrm{~m}$ depth using a conductivity meter Cond $315 \mathrm{i}$ (Wissebschaftlich-Technische Werkstätter GmbH, Weilheim, Germany). Each piece was placed in a pre-labelled (line number and position on the line) plastic bag and stored at $-20{ }^{\circ} \mathrm{C}$. The seawater-saturated wood blocks were then freeze-dried because this is less aggressive than oven-drying methods and preserves both the wood block structure and possible woodborers inside. After this step, the surfaces of the blocks were carefully cleaned from epi-fauna and -flora colonizing the surface before being individually weighed again. Wood decay was then expressed in terms of mass loss. The amount (in \%) of wood remaining after a given time interval was calculated for every single wood piece as the ratio between the weight of wood after the exposure time (Wt) and the initial weight of the wood board (Wi), multiplied by 100 .

Intensity of wood borer attack

The cleaned surface of each dried wood block was examined using a stereomicroscope to locate, characterize and count the attacks by marine borers. Using this approach it is only 
possible to determine the number of successful attacks by individuals since a "success" is defined as piercing and boring into the wood sufficiently to leave a hole.

\section{Modelling}

The modelling design assumed that the mass loss of the wood pieces should be represented by a minimal function, with the smallest number of parameters to identify by optimization. The apparent mass loss of the wood boards may result from the cumulative effect of different factors (Björdal and Nilsson, 2005) but the observable effect expected over the short period of the experiment (one year) in marine water was assumed to be mainly driven by the colonization of wood-boring species (using wood as a food source).

Therefore, from an initial time $t_{i}$ related to the first wood-borer recruitment, the minimal dynamics of the mass of the wood samples can be described by:

The discrete change in the remaining mass of wood, B (either in total weight or in \% of the initial wood plank weight, $\mathrm{B}_{0}$ ), between times $\mathrm{t}$ and $\mathrm{t}+1$ can be formulated as:

$$
B_{t+1}=B_{t}-k B_{t} T_{t}\left(1-\frac{B_{\text {min }}}{B_{t}}\right) \Delta t
$$

where $\mathrm{k}$ (individual ${ }^{-1} \mathrm{day}^{-1}$ ) accounts for the consumption rate of wood by the wood borers, $\mathrm{B}_{\min }\left(\mathrm{B}_{\min }<\mathrm{B}_{0}\right)$ the part of wood that remained unavailable to wood borers (either in total weight or in $\%$ of the initial wood plank weight), and with a consecutive change in the number of wood-borers, $\mathrm{T}$ (in number of individuals) represented by:

$$
T_{t+1}=T_{t}+\alpha\left(1-\frac{T_{t}}{T_{c}}\right) \Delta t
$$$$
\text { eq. } 2
$$

where $\alpha$ (number of individuals.day ${ }^{-1}$ ) is the arrival rate of the wood borers and $\mathrm{T}_{\mathrm{c}}$ is the maximum number of wood borers that can colonize the plank sample $\left(T_{c}>T_{0}\right)$. 
Optimal values for the 5-parameters $\left\{\mathrm{t}_{\mathrm{i}}, \alpha, k, \mathrm{~T}_{\mathrm{c}}, \mathrm{B}_{\min }\right\}$ were determined by fitting the model to the observations, fixing the initial conditions $\left(\mathrm{B}_{0}=100\right.$ and $\left.\mathrm{T}_{0}=0\right)$ and minimizing a least square criterion using the Nelder and Mead simplex algorithm (Nelder and Mead, 1965). The equations above along with the optimization procedure were programmed and calculated using SciLab (SciLab Enterprises, 2012).

\section{Results}

Water temperature and salinity measured at the study site during the sampling ranged from 16.0 to $22.8{ }^{\circ} \mathrm{C}$ and from 34.9 to 37.4 , respectively.

Wood mass loss observed

Dynamics of wood mass is presented in Fig. 1. Under the hypothesis of independence of the sampling, we found that the wood mass significantly decreased between two sampling times (Kruskal Wallis test, $\mathrm{k}=4, \mathrm{n}_{\mathrm{k}}=5, \mathrm{p}<0.001$, then Dunn's test, post-hoc multiple comparison tests to detect differences between exposure times, $\mathrm{p}<0.01$ for each pairwise comparison). From this, we inferred that the dynamics of wood mass loss exhibited three distinct phases: an initial phase of latency followed by a sharp decrease in mass loss that ended with a third phase during which the weight loss rate slowed down considerably. First estimates show that, from April to June, the wooden blocks lost on average about $0.05 \%$ of their mass per day. Then, this mean daily loss rate quickly rose to $0.38 \%$, before falling to $0.05 \%$ after November.

Wood borer attack 
The general aspect of, and hence the bulk volume of the wood blocks remained generally unchanged over the experiment. However, close inspection of the surface of the blocks revealed the presence of small holes that accounted for wood attacks by wood-feeding marine bivalves. The size of the holes was less than $1 \mathrm{~mm}$; some of these holes showed calcareous linings; and small paddle-shaped calcareous structures, the pallets, were visible inside the burrows. These clues indicated the colonization of the planks by wood-boring molluscs that belonged to the Teredinidae (Turner, 1971). No wood-boring isopod or amphipod was observed. The number of shipworm attacks increased concomitantly with the decrease of wood mass (Fig. 1). Starting at less than $60 \pm 30$ (mean \pm SD) after 97 days of exposure, the mean number of holes per board increased by hundreds and stabilized after 208 days to reach $1492 \pm 94$ individuals $\left(6.58 \pm 0.41\right.$ individuals per $\left.\mathrm{cm}^{2}\right)$ by the end of the experiment.

Modelling wood mass loss

Results of the simulation and optimized estimated values of the parameters in the model are shown in Table 1. The model fitted to the experimental dataset is presented in Fig 1. The modelling also showed three stages in the weight loss of the wood blocks. The decrease in mass, initially slow, accelerated and then slowed down again, reaching $48 \%$ by the end of the simulation time.

This modelling suggested that the arrival of shipworms on wood boards started about two months (53 days, Table 1) after the submersion of the wood logs. From this time onward, the number of shipworms that colonize the plank increased at an estimated rate of 7 to 8 individuals per day to reach 1,545 individuals by the end of the simulation time. The saturation density of the planks by shipworms was estimated to be close to 2,180 individuals (Table 1).

\section{Discussion}


The loss of wood mass at sea is actually the cumulative effect of biological degradation that depends on environmental factors such as oxygen content, temperature and salinity (Bienhold et al., 2013; Fors et al., 2014; Björdal and Nilsson, 2008; Fojutowski et al., 2014; Nishimoto et al., 2015). During this experiment, ranges of water temperature and salinity were rather high and narrow, matching temperature and salinity tolerances of most shipworm species occurring in European waters (Borges et al., 2014). Under such conditions, these organisms are involved in wood decomposition well before microbial attack becomes important (Bjordal and Nilsson, 2008; Nishimoto et al., 2015). Based on the observed dynamics of both wood decay and boring hole numbers, as well as the presence of pallets and calcareous linings, wood mass loss was primarily attributed to shipworm activity.

At the mouth of the Massane River, shipworms were efficient agents of wood decay. Through their activity, the initial mass of wood blocks was decreased by half within 6 months of wood submersion in seawater. Once settled, shipworms begin to bore the wood surface (Isham and Tierney, 1953). Teredinidae dig one-way galleries and line the wall of their wormlike tunnel with a thin calcareous coating. The mechanical extraction of wood borers and fresh water flushing of the interior part of the wood log was not attempted, because of the amount of entanglement and the extreme fragility of the biostructures within the wood matrix (Nishimoto et al., 2015). It is thus worth noting that the exact remaining mass of wood was slightly less than the apparent weight of the boards (which included dried flesh, shells, pallets, the calcareous lining of shipworms tunnels). The weight of these combined parts was assumed to be small in comparison to that of wood itself (Nishimoto et al., 2015). The drilling effect of the shipworms was high enough to measure wood mass loss resulting from their destructive activity. Therefore, overall wood weight decreased and wood mass loss did not fall below a critical value, which is the part of wood that remained unavailable to removal by shipworms. 
The overall dynamics of the mass loss of wood blocks over time had the shape of a negative sigmoidal curve (Fig. 1). Several mathematical functions including the most generic one, the polynomial curve, can have the same trend. Such curve-fittings are very convenient because their parameters can be used for comparisons from one degradation study to another. However, these approaches do not explicitly account for processes observed (Freschet et al., 2012; Webster and Benfield, 1986). Instead of fitting a curve to our data, we formulated a minimal model, based on a simplified conceptualization of the system investigated, which linked the colonization of wood boards by wood borers with the resulting loss of wood mass (as it could be observed during the experiment).

During the experiment, shipworm attacks occurred before the end of the first time of exposure that is to say during the first 97 days. Mediterranean marine borers do not permanently produce larvae (Roch 1940). Besides, adult populations, especially long-term brooding species, must be present in the area for expecting the recruitment of juveniles on new substrates (McIntosh et al., 2012; Nishimoto et al., 2015). The result of the optimization process with the model suggested that the arrival of shipworms on wood blocks started 53 days (Table 1) after submersion. This estimate dates the recruitment of shipworms to the beginning of June, in agreement with previous surveys of the recruitment of several shipworm species in the Mediterranean Sea (Roch, 1940).

After the start of colonization, the number of holes in the wood blocks reflected the maximum number of shipworm attacks responsible for the apparent mass loss of the wood pieces. This number increased to reach, by November, a total of $c a$. 1,500 individuals. Within the same duration (around 6 months) the apparent weight of the wood blocks was decreased by about half $\left(\mathrm{B}_{\min }=52 \%\right.$, Table 1$)$. Then, the rate of wood degradation slowed down suggesting that degradation of the blocks depended no longer on the direct effect of shipworms but on other biological and physical processes (Björdal and Nilsson, 2008; 
Nishimoto et al., 2015). Shipworm attacks were not evenly distributed on the surface of wood blocks. Borers competed for space with congeners but also with other colonizers. We noticed that coverage of the boards by biofouling fauna increased with the length of stay of the blocks in water, but this did not prevent shipworm recruitment; the mean number of shipworm attacks increased with time exposure.

Dynamics of wood decay at sea depends not only on environmental drivers but also on the chemical and structural traits of the individual wood pieces and logs (Björdal and Nilsson, 2008; Fojutowski et al., 2014; Nishimoto et al., 2015). Among the intrinsic properties of CWD, the surface-to-volume ratio has special importance for degradation rates. Surface-tovolume ratios of substrates and decay rates are strongly correlated (Webster et al., 1999). Natural wood substrates (twigs, branches) have surface-to-volume ratios ranging from 1 to 3 (Spänoff and Meyer, 2004). The surface-to-volume ratio of the wood blocks we used was 1.3. In this respect, rates and parameters of decay would be representative of natural CWD. Wood drilling by shipworms leads to a strong increase of the surface-to-volume ratio that can speed

up the decomposition of wood by micro-organisms (Björdal and Nilsson, 2008). The action of shipworms weakens the structural integrity and resistance of wood and promotes dislocations by mechanical processes (shock, shear stress due to waves, currents and weight of encrusted epibiota), probably hastening the complete decay of CWD, depending on the depositional condition and environment.

\section{Conclusion}

The wooden blocks we used in our study have lost up to $0.38 \%$ of their mass daily, primarily because of the activity of marine borers. A dense population of shipworms can reduce by more than half the mass of sapwood blocks of pine in less than six months. Even though weighing the experimental wood blocks does not determine the full extent to which the borers 
can remove wood from the interior, there is a need to estimate the limit below which the "population" growth is regulated by crowding. This suggests that additional modelling must be performed to understand how the morphological and demographic characteristics of wood borers interact with the volume and geometry of dead wood debris during the degradation process. To achieve this, high-resolution 3D X-ray imaging could be used in future studies to assess wood losses in terms of volume rather than mass, and hence be used to parameterize an individual based model for the colonization of the wood. Beyond the effect of borers, marine systems are environments in which dead wood is subjected to rapid degradation. Steep Mediterranean forested watersheds drained by rivers with torrential regimes are active systems that supply the adjacent coastal marine environments with recurrent inputs of woody materials that support locally important marine communities. Quantifying transfer and turnover of dead wood is thus an important future challenge to fully understanding the functioning of oligotrophic Mediterranean ecosystems.

\section{Acknowledgments}

This work was supported by the EC2CO (Écosphère Continentale et Côtière) national program of the CNRS-INSU, as part of the DRIL (Dynamique et Réactivité des Interfaces Littorales) topics, under the title: "De la forêt à la Mer : Transfert et recyclage du bois mort sur la marge continentale méditerranéenne. We acknowledge Jan Ellis and Alan Foster for the language revision of the first draft of the manuscript. We are also grateful to Joseph Garrigue, curator of the Réserve Naturelle Nationale de la forêt de la Massane for sharing his expert knowledge of the forest landscapes in the region. 
References:

Amon, D.J., Sykes, D., Ahmed, F., Copley, J.T., Kemp K.M., Tyler, P.A., Young, C.M., Glover, A.G., 2015. Seeing in the dark: Ecosystem functions of the wood-boring genus, Xylophaga revealed by micro-computed-tomography. Front Mar Sci 2:10 doi: 10.3389/fmars.2015.00010

Bienhold, C., Pop Ristova, P., Wenzhöfer, F., Dittmar, T., Boetius, A., 2013. How deepsea wood falls sustain chemosynthetic life. PLoS ONE 8, e53590. doi:10.1371/journal.pone.0053590

Björdal, C.G., Nilsson, T., 2008. Reburial of shipwrecks in marine sediments: a long-term study on wood degradation. J. Archaeol. Sci. 35, 862-872

Borges, L.M., Merckelbach, L.M., Sampaio, I., Cragg, S.M., 2014. Diversity, environmental requirements, and biogeography of bivalve wood-borers (Teredinidae) in European coastal waters. Front. Zool. 11, 1-13.

Charles, F., Coston-Guarini, J., Lantoine, F., Guarini, J.-M., Yücel, M., 2014.

Ecogeochemical fate of coarse organic particles in sediments of the Rhône River prodelta. Est. Coast. Shelf S. 141, 97-103. doi:10.1016/j.ecss.2014.03.005

Dickinson, C.H., Pugh, G.J.F., 1974. Biology of Plant Litter Decomposition, Volume 2, 1974, Academic Press, London. 
Fojutowski, A., Wróblewska, H., Komorowicz, M., Kropacz, A., Noskowiak, A., Iwona Pomian, I., 2014. Changes in the properties of English oak wood (Quercus robur L.) as a result of remaining submerged in Baltic Sea waters for two years. Internat. Biodeter. Biodegrad. 86, 122-128.

Fors, Y., Grudd, H., Rindby, A., Jalilehvand, F., Sandström, M., Cato, I., Bornmalm, L., 2014. Sulfur and iron accumulation in three marine-archaeological shipwrecks in the Baltic Sea: the Ghost, the Crown and the Sword. Sci Rep. 4, 4222. doi: 10.1038/srep04222.

Freschet, G.T., Weedon, J.T., Aerts, R., van Hal, J.R., Cornelissen, J.H.C., 2012. Interspecific differences in wood decay rates: insights from a new short-term method to study long-term wood decomposition. J. Ecol. 100, 161-170. doi:10.1111/j.13652745.2011.01896.x

Harmon, M.E., Franklin, J.F., Swanson, F.J., Sollins, P., Gregory, S.V., Lattin, J.D., Anderson, N.H., Cline, S.P., Aumen, N.G., Sedell, J.R., Lienkaemper, G.W., Cromack Jr, K., Cummins, K.W.,1986. Ecology of coarse woody debris in temperate ecosystems. Adv. Ecol. Res. 15, 133-302.

Isham, L.B., Tierney, B.Q., 1953. Some aspects of the larval development and metamorphosis of Teredo (Lyrodus) pedicellata de Quatrefages. B. Mar. Sci. of the Gulf and Caribbean 2, 574-589. 
Nelder, J.A., Mead, R., 1965. A simplex method for function minimization. Comput. J. 7, $308-313$.

Nishimoto, A., Haga, T., Asakura, A., Shirayama, Y., 2015. An experimental approach for understanding the process of wood fragmentation by marine wood borers in shallow temperate waters. Mar. Ecol. Prog. Ser. 538,53-65.

Roch, F., 1940. Die Teredinidae des Mittelmeeres. Thalassia 4, 1-147.

Sabaté, S., Gracia, C.A., Sánchez, A., 2002. Likely effects of climate change on growth of Quercus ilex, Pinus halepensis, Pinus pinaster, Pinus sylvestris and Fagus sylvatica forests in the Mediterranean region. For. Ecol. Manage. 162, 23-37.

Scilab Enterprises, 2012. Scilab: Free and Open Source software for numerical computation (OS, Version 5.5.0) [Software]. Available from: http://www.scilab.org

Spänhoff, B., Meyer, E.I., 2004. Breakdown rates of wood in streams. J. N. Am Benthol. Soc. 23, 189-197. doi:10.1899/0887-3593

Thiel, M., Haye, P.A., 2006. The ecology of rafting in the marine environment. III. Biogeographical and evolutionary consequences, in: Gordon, J.D.M., Atkinson, R.J.A., Gibson, R.N. (Eds.) Oceanography and marine biology — an annual review, Vol 44. CRC Press, Boca Raton, FL, p 323-429. 
Thiel, M., Hinojosa, I.A., Joschko, T., Gutow, L., 2011. Spatio-temporal distribution of floating objects in the German Bight (North Sea). J. Sea Res. 65, 368-379. doi:10.1016/j.seares.2011.03.002

Turner, R.D., 1971. Identification of marine wood boring mollusks of the world. in :

Gareth Jones, E.B., Eltringham, S.K. (Eds) Marine borers, fungi and fouling organisms of wood. Proceedings of the OECD workshop organised by the committee investigating the preservation of wood in the marine environment, $27^{\text {th }}$ march- $3^{\text {rd }}$ April 1968. p. 17-64.

Webster, J.R., Benfield, E.F., Ehrman, T.P., Schaeffer, M.A., Tank, J.L., Hutchens, J.J., D'Angelo, D.J., 1999. What happens to allochthonous material that falls into streams? A synthesis of new and published information from Coweeta. Freshwater Biol. 41, 687-705.

Webster, J. R., Benfield, E. F., 1986. Vascular plant breakdown in freshwater ecosystems. Ann. Rev. Ecol. Sys. 17, 567-594. doi:10.1146/annurev.es.17.110186.003031

West, A.J., Lin, C. W, Lin, T.C., Hilton, R.G., Liu, S. H., Chang, C.T., Lin, K.C., Galy, A., Sparkes, R.B., Hovius, N., 2011. Mobilization and transport of coarse woody debris to the oceans triggered by an extreme tropical storm. Limnol. Oceanogr. 56, 77-85. 
Table 1 Optimized values of the parameters and rates of the model.

\begin{tabular}{lll}
\hline Constant & Unit & Value \\
\hline Latency time & days & 53 \\
$\alpha$, arrival rate & shipworms day & -1 \\
$T c$, maximum number of shipworms & shipworms & 7.67 \\
$k$, consumption rate & shipworm $^{-1}$ day $^{-1}$ & 2180 \\
$B c$, wood unavailable to consumption by shipworms & $\%$ of the initial wood weight & 52 \\
& & 0.000018 \\
\hline
\end{tabular}


Fig. 1 Decay dynamics of pine planks submerged at the mouth of the Massane River, Mediterranean Sea, France, from 18 April 2014 to 23 May 2015. Dots account for individual wood mass and population density of shipworms for each sample; curves account for best-fit model estimates for wood decay and colonization by shipworms.

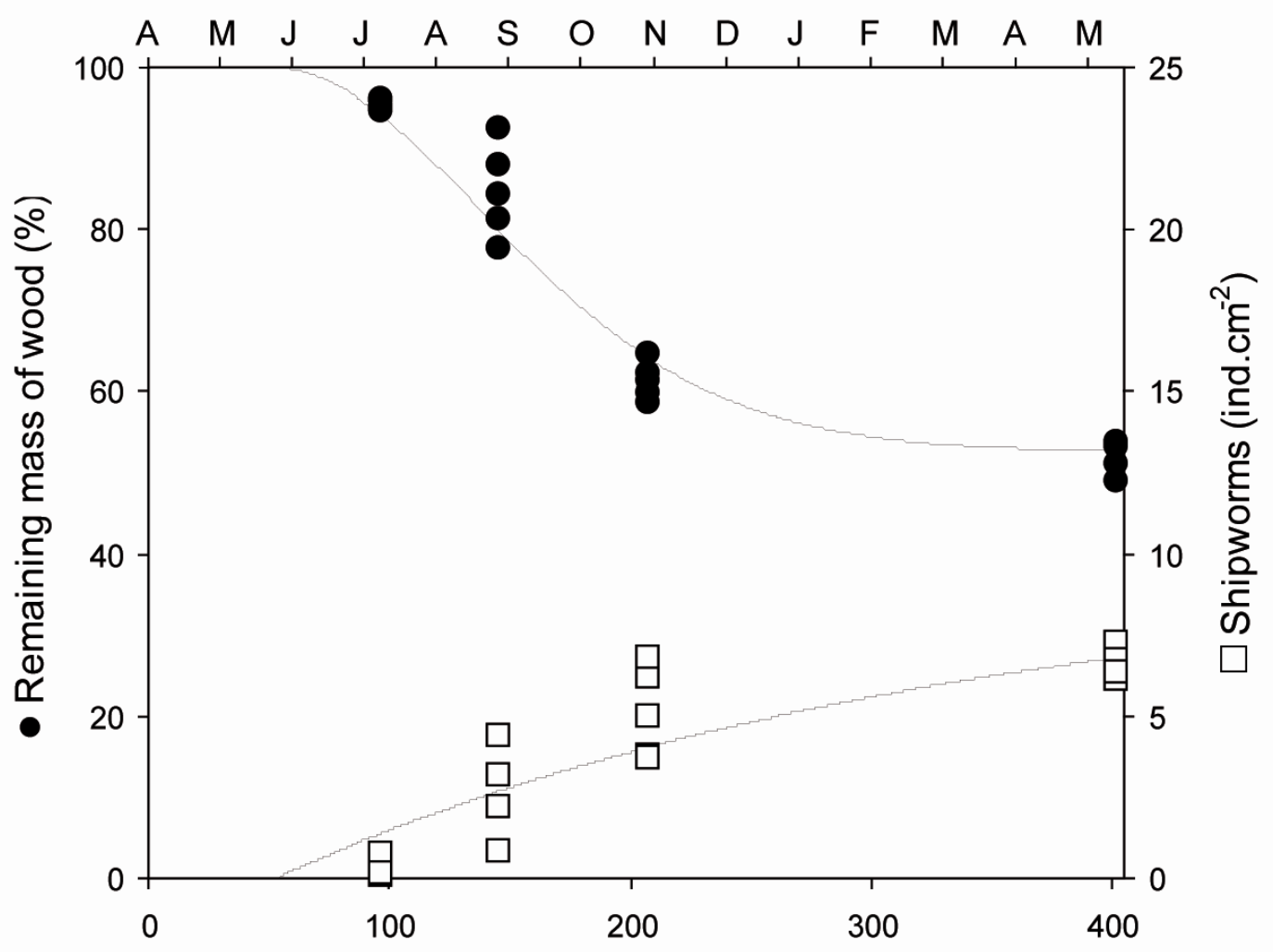


Highlights :

- How fast does deadwood break down at sea?

- The apparent weight of sapwood pine blocks halved in less than 6 months.

- Blocks lose up to $0.38 \%$ of their mass daily because of the activity of wood borers.

- $\quad$ Shipworm communities are responsible for early, rapid wood decay process at sea 